\title{
A Convenient, High Yielding Cleavage of the Thiocarbonyl Group in Xanthates ${ }^{\dagger}$
}

\author{
Béatrice Quiclet-Sire* and Samir Z. Zard* \\ Laboratoire de Synthèse Organique, CNRS UMR 7652, Ecole Polytechnique, 91128, Palaiseau, France \\ *E-mail: sire@poly.polytechnique.fr (B. Q.-S.); zard@poly.polytechnique.fr (S. Z. Z.) \\ Received October 24, 2009, Accepted November 26, 2009
}

Key Words: Xanthates, Ozonolysis, Thiolcarbonates, RAFT polymers

As part of our ongoing studies on the degenerative radical transfer reactions of xanthates and related derivatives, ${ }^{1}$ we required an effective, general, and ecologically acceptable procedure for the cleavage of the thiocarbonyl group in the product and its replacement by a carbonyl. Several procedures have been described in the literature for performing such a transformation. ${ }^{2}$ They involve various metal salts such as mercuric acetate, cupric chloride, and silver nitrate, ${ }^{3} \mathrm{~N}$-bromo- or $\mathrm{N}$-iodosuccinimide, ${ }^{4}$ sodium nitrite/ $\mathrm{HCl}^{5}$, peracids, $^{6}$ singlet oxygen, ${ }^{7}$ phenylseleninic acid or anhydride, and dianisyl telluroxide. ${ }^{8}$ More recently Barba and co-workers accomplished the conversion of a xanthate into a thiolcarbonate by anodic oxidation. ${ }^{9}$

Selenium and tellurium based reagents are the mildest and perhaps the most generally useful but they are not adapted for large scale work. We therefore turned to ozone as a potential cleaving agent. An early study by Zwanenburg and Janssen reported the formation of sulfines from hindered thioketones and dithioesters. ${ }^{10 a}$ The sulfines in turn can be cleaved by ozone. Unhindered substrates gave the corresponding carbonyl derivatives directly and no sulfine intermediate could be detected, but only three examples were examined. The formation of sulfines in the case of hindered thioketones was confirmed in two more recent studies ${ }^{10 b, c}$ and one report mentions the reaction of ozone with a dithiocarbonyl sulfone, but the yield in the example described is modest. ${ }^{10 \mathrm{~d}}$ We have used ozone in the past to convert a sulfine into a ketone in a successful approach for the degradation of the bile acid side-chain. ${ }^{11}$

In the context of our work, we needed to examine the applicability of ozone to cleaving the thiocarbonyl group of xanthates. In the event, passing a stream of ozone in oxygen into a solution of xanthate $1 \mathrm{a}$ in dichloromethane at $-78{ }^{\circ} \mathrm{C}$ for a few minutes caused a relatively clean transformation into the corresponding thiolcarbonate $\mathbf{3 a}$; however, the solid crude material obtained upon evaporation of the solvent was quite dark in color and darkened further upon standing. Chromatographic purification provided pure 3a in $80 \%$ yield. Despite the good yield, the experimental procedure was clearly not satisfactory. We reasoned that the formation of sulfur trioxide and possibly sulfuric acid, the co-products of the reaction, could be the cause of the partial decomposition of the product or starting material leading to highly colored side-products. Our reasoning hinges on the reaction mechanism displayed in Scheme 1, adapted from the mechanism proposed earlier by Zwanenburg and Jan-

${ }^{\dagger}$ This paper is dedicated to Professor Sunggak Kim on the occasion of his honorable retirement. ssen. ${ }^{10 a}$ Structures $\mathbf{4}$ and $\mathbf{5}$ are only hypothetical since the fragmentation of intermediate $\mathbf{2}$ may not proceed by the route shown. In a non-polar medium, the substrate and the product are extensively protonated by a strong acid such as sulfuric acid since the effective acidity is much greater than in a protic solvent. $^{12}$

We therefore repeated the experiment, substituting the dichloromethane with wet acetone in order to destroy any sulfur trioxide and limit the deleterious effect of the sulfuric acid produced. With this simple modification, the crude product was already a white solid before chromatographic purification. Moreover, we could now perform the ozonolysis at room temperature, which is a valuable advantage when operating on a large scale. The formation of sulfuric acid as the co-product was

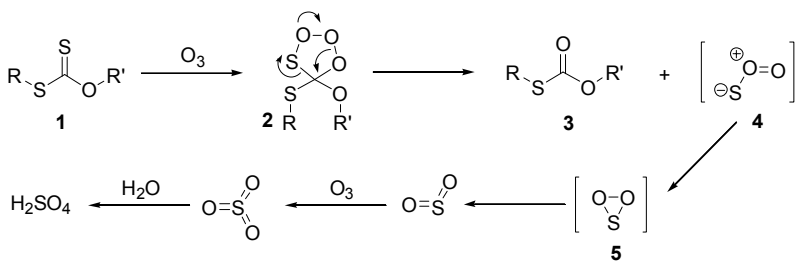

Scheme 1. A possible mechanism for the ozonolysis of a xanthates

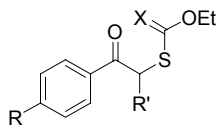

1a, $\mathrm{R}=\mathrm{OMe} ; \mathrm{R}^{\prime}=\mathrm{H} ; \mathrm{X}=\mathrm{S}$

a, $R=O M e ; R^{\prime}=H ; X=O(84 \%)$

$1 \mathbf{b}, \mathrm{R}=\mathrm{F} ; \mathrm{R}^{\prime}=\mathrm{H} ; \mathrm{X}=\mathrm{S}$

3b, $\mathrm{R}=\mathrm{F} ; \mathrm{R}^{\prime}=\mathrm{H} ; \mathrm{X}=\mathrm{O}(84 \%)$

c, $R=F ; R^{\prime}=M e ; X=S$

3c, $R=F ; R^{\prime}=M e ; X=O(80 \%)$

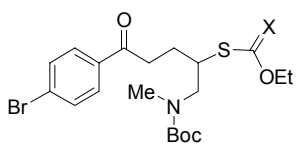

$1 \mathrm{~h}, \mathrm{X}=\mathrm{S}$

$3 h, X=O(64 \%)$

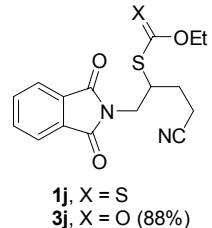

$$
\underbrace{X_{S}^{O E t}}_{R^{\prime}}
$$

1d, $R=O E t ; R^{\prime}=M e ; X=S$

3d, $R=O E t ; R^{\prime}=M e ; X=O(66 \%)$

1e, $R=$ cyclopropyl; $R^{\prime}=H ; X=S$

3e, $R=$ cyclopropyl; $R^{\prime}=H ; X=O(80 \%)$

1f, $R=$ EtO; $R^{\prime}=H ; X=S$

3f, $R=$ EtO; $R^{\prime}=H ; X=O(77 \%)$

1g, R $=\mathrm{PhCO}_{2} \mathrm{CH}_{2} ; \mathrm{R}^{\prime}=\mathrm{H} ; \mathrm{X}=\mathrm{S}$

3g, $\mathrm{R}=\mathrm{PhCO}_{2} \mathrm{CH}_{2} ; \mathrm{R}^{\prime}=\mathrm{H} ; \mathrm{X}=\mathrm{O}(82 \%)$
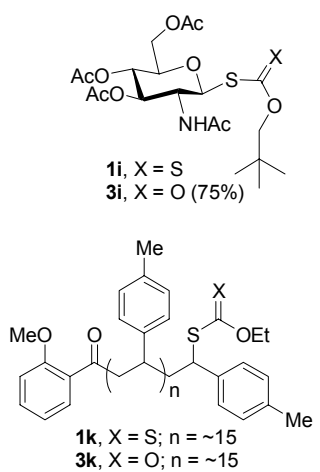

Scheme 2. Examples of thiocarbonyl group cleavage 


$$
\begin{aligned}
& \text { 1) } \mathrm{O}_{3} \text {, dichloromethane } \\
& -78^{\circ} \mathrm{C} \\
& \text { (Sudan III end-point indicator) }
\end{aligned}
$$

Scheme 3. Chemoselective ozonolysis of an alkene in the presence of a xanthate

confirmed by precipitation of barium sulfate upon addition of barium hydroxide to the aqueous phase.

With a good procedure in hand, we explored the scope of this method for the cleavage of the thiocarbonyl group in xanthates. Our results are shown in Scheme 2. In all cases, the reaction was complete in a few minutes and the crude product was sufficiently pure for further transformations. On small scale, purification by column chromatography was more convenient.

A typical procedure is as follows: A stream of ozone diluted in oxygen (BMT 802X Ozone Generator) was bubbled through a solution of xanthate $1(0.74 \mathrm{mmol})$ in acetone containing $2.5 \%$ water $(8 \mathrm{~mL})$ for 7 minutes. The ozone generator was turned off and oxygen was allowed to pass through the solution for a few minutes to flush out any remaining ozone. The solvent was evaporated and the residue taken up in a little dichloromethane, and dried over sodium sulfate. Evaporation and chromatography over silica gel gave the pure thiolcarbonate $\mathbf{3}$, in the yield shown in Scheme 2.

One especially useful application of this reaction is the modification of the xanthate group in polymers and block copolymers obtained by the RAFT/MADIX controlled radical polymerization process. ${ }^{13}$ Indeed, upon ozonolysis for a few minutes of polymer $1 \mathbf{k}$, obtained by the polymerization of 4methylstyrene, the characteristic bands for the xanthate at 1215 and $1052 \mathrm{~cm}^{-1}$ disappeared and were replaced by bands at 1705 and $1140 \mathrm{~cm}^{-1}$ typical of thiolcarbonates. The removal of the thiocarbonyl group eliminates the potential source of unacceptable odor that could in time emanate from RAFT/MADIX type polymers through hydrolytic or photolytic degradation. The sulfur that remains in product $\mathbf{3 k}$ is solidly attached to the polymer chain and cannot be easily cleaved off. It is therefore unlikely to cause any stench. Incidentally, the treatment with ozone also removes any undesirable color and residual unreacted monomer, and improves therefore significantly the quality of the polymer. ${ }^{14}$

While performing these ozonolysis experiments, the question arose as to whether the thiocarbonyl group reacted with ozone at a faster or slower rate than a simple alkene. To answer this question, we prepared compound $\mathbf{1 l}$ and exposed it to a stream of ozone in the presence of a very small amount of Sudan Red III dye. The flow of ozone was interrupted when the medium was discolored. It was important to have an end point indicator in order to achieve maximum chemoselectivity. Upon work up, we were pleased to find that ketone $\mathbf{6}$ could be isolated in $70 \%$ yield, along with only a small amount of thiolcarbonate $7(8 \%)$. This observation has very interesting synthetic applications since it indicates that alkenes can be cleaved into the corresponding carbonyl derivatives in the presence of the xan- thate group, allowing thus access to structures otherwise not directly accessible.

In summary, we have developed a very simple conversion of the thiocarbonyl group in xanthates into a carbonyl using ozone in wet acetone. This method differs from the previous methods in one important aspect. While most described reagents cleave the thiocarbonyl group without affecting an alkene in the molecule (see for example ref. 7e), the present ozone based transformation allows the prior chemoselective cleavage of the alkene before the xanthate.

\section{References}

1. For reviews of the xanthate transfer, see: (a) Zard, S. Z. Angew. Chem., Int. Ed. Engl. 1997, 36, 673-685. (b) Zard, S. Z. In Radicals in Organic Synthesis; Renaud, P., Sibi, M. P., Eds; Wiley-VCH: Weinheim, 2001; Vol. 1, pp 90-108. (c) Quiclet-Sire, B.; Zard, S. Z. Chem. Eur. J. 2006, 12, 6002-6016. (d) Quiclet-Sire, B.; Zard, S. Z. Top. Curr. Chem. 2006, 264, 201-236. (e) Zard, S. Z. Aust. J. Chem. 2006, 59, 663-668. (f) Zard, S. Z. Org. Biomol. Chem. 2007, 5, 205-213.

2. For a review, see: Corsaro, A.; Pistara, V. Tetrahedron 1998, 54, 15027-15062.

3. (a) Durand, T.; Guy, A.; Vidal, J.-P.; Rossi, J.-C. J. Org. Chem. 2002, 67, 3615-3624. (b) Demyuck, C.; Thuillier, A. Bull. Soc. Chim. Fr. 1969, 2434-2438. (c) Cristol, S.; Seapy, D. G. J. Org. Chem. 1982, 47, 132-136. (d) Lieser, T.; Leckzyck, E. Ann. 1935, 519, 279-291. (e) Makens, R. F. J. Am. Chem. Soc. 1935, 57, 405-406.

4. Furuta, S.; Kuroboshi, M.; Hiyama, T. Bull. Chem. Soc. Jpn. 1999, $72,805-820$

5. Jorgensen, K. A.; Ghattas, A.; Lawesson, S.-O. Tetrahedron 1982 , 38, 1163-1168.

6. (a) Back, T. G.; Barton, D. H. R.; Britten-Kelly, M. R.; Guziec Jr, F. S. J. Chem. Soc., Chem. Commun. 1975, 539; J. Chem. Soc., Perkin Trans. 1 1976, 2079-2089. (b) Elsaesser, A.; Sudermeyer, W.; Stephenson, D. S. Chem. Ber. 1985, 118, 116-123. (c) Le Nocher, A.-M.; Metzner, P. Tetrahedron Lett. 1991, 32, 747-750. (d) Marrière, E.; Chevrie, D.; Metzner, P. J. Chem. Soc., Perkin Trans. 1 1997, 2019-2020. (e) Ohno, A.; Nakamura, K.; Nakazima, Y.; Oka, S. Chem. Lett. 1975, 983-984.

7. Rao, V. J.; Muthuramu, K.; Ramamurthy, V. J. Org. Chem. 1982, $47,127-131$

8. (a) Cussans, N. J.; Ley, S. V.; Barton, D. H. R. J. Chem. Soc., Perkin Trans. 1 1980, 1650-1653. (b) Barton, D. H. R.; Finet, J.-P.; Thomas, M. Tetrahedron 1986, 42, 2319-2324. (c) Barton, D. H. R.; Crich, D.; Löbberding, A.; Zard, S. Z. Tetrahedron 1986, 42, 23292338. (d) Barton, D. H. R.; Finet, J.-P.; Thomas, M. Z. Tetrahedron 1986, 42, 2319-2324. (e) Alameda-Angulo, C.; Quiclet-Sire, B.; Zard, S. Z. Tetrahedron Lett. 2006, 47, 913-916.

9. Batanero, B.; Picazo, O.; Barba, F. J. Org. Chem. 2001, 66, 320-322.

10. (a) Zwannenburg, B.; Janssen, W. A. Synthesis 1973, 617-620. (b) Ramnath, N.; Ramesh, V.; Ramamurthy, V. J. Chem. Soc., Chem. Commun. 1981, 112-114. (c) Tabuchi, T.; Nojima, M.; Kusabayashi, S. J. Chem. Soc., Chem. Commun. 1990, 625-629; J. Chem. Soc., Perkin Trans. 1 1991, 3043-3046. (d) Holm, S.; Boerma, J. A.; Nilsson, N. H.; Senning, A. Chem. Ber. 1976, 109, 1069-1074.

11. Barton, D. H. R.; Wozniak, J.; Zard, S. Z. Tetrahedron 1989, 45, 3741-3754.

12. For a recent discussion on solvent effects in chemical reactions, see: Reichardt, C. Org. Process Res. Dev. 2007, 11, 105-113. A notable solvent effect was observed in the ozonolysis of thiouracil: Claudia, C.; Mincione, E.; Saladino, R.; Nicoletti, R. Tetrahedron 1994, 50, 3259-3272.

13. For recent reviews, see: Handbook of RAFT Polymerization; Barner-Kowollik, C., Ed.; Wiley-VCH: Weinheim, 2008. (b) Moad, G.; Rizzardo, E.; Thang, S. H. Aust. J. Chem. 2006, 59, 669-692. (d) Moad, G.; Rizzardo, E.; Thang, S. H. Aust. J. Chem. 2005, 58, 379-410. (c) Perrier, S.; Takolpuckdee, P. J. Polym. Sci. Part A: Polym. Chem. 2005, 43, 5347-5397.

14. This procedure for oxidizing polymers containing xanthates and related dithiocarbonyl end-groups has been patented: Zard, S. Z.; Sire, B.; Jost, P. Int. Pat. WO 20050402332005. 